\title{
Bernike Pasveer, Oddgeir Synnes and Ingunn Moser (eds) (2020) Ways of Home Making in Care for Later Life. London: Palgrave Macmillan. 312 pages. ISBN: 9789811504051
}

\author{
Doris Lydahl \\ doris.lydahl@gu.se
}

Throughout the Western world a paradigm of "ageing-in-place" is expanding. According to this paradigm, we are facing a twofold crisis of a rapidly ageing population on the one hand, and a care deficit on the other. As a response to this problem the provision of home care is increasingly regarded as a gold standard for the organisation of care. Ways of Home Making in Care for Later Life wants to critically engage with the expanding paradigm of ageing-in-place by asking how home is made when it intersects with new forms of care as a result of ageing. In the current political ageingin-place discourse home is seen as a noun - a singular, stable and given location "that naturally affords the inhabitant to live and age well" (p. 3). Building on a material semiotic approach, this book seeks to question this discourse and instead proposes an understanding of home as a verb a making, which requires relations and arrangements between different actors, such as older persons, care workers, doors, technologies, spaces and policies to name a few.

Altogether, this is a welcome, thoughtprovoking, and intriguing book. Theoretically and

methodologically rigorous - yet, accessible and comprehensive - it will be of significance to anyone interested in research about health, place, age, and society. Home making in and with care has not been systematically introduced before, and the authors of this volume successfully show why it is important to pay attention to how home is made when care enters the lives of people as they grow old at home or in 'homely' institutions.
The editorial introduction challenges the ageing-in-place discourse by offering three lessons. The first is that doing home with care is a material and situated practice. This important message is reminiscent of the authors' previous work. In prior publications the very practices of care were in focus, and it was argued that care is a material and situated practice (Mol et al., 2010). The second lesson is more political. The authors want nothing less than to fiercely challenge the view of home making in care for later life as all about "independence and autonomy and control" (p. 13). Home making with care is instead about new modes of becoming entangled. Growing old with care, the authors argue, is therefore about "learning to become dependent" (p. 13, italics in original). The final message is that the authors do no shy away from the normativities of their own stories and concerns. Rather, the authors underscore the importance of moving and thinking with the many makers of home with care. In line with feminist scholars, the authors point to the importance of situated knowledge and their responsibilities as researchers (Haraway, 1988; Puig de la Bellacasa, 2011).

This edited volume is part of the Health, Technology \& Society series that has already published more than twenty books on recent developments with health technologies in various areas. The book addresses a range of geopolitical context (with a clear pull towards Norway) and authorship covers a range of disciplines including medical anthropology, science and technology studies, 
narrative medicine, and psychology. Consisting of fourteen chapters the volume is organized in three main parts. Drawing on array of qualitative methods including autoethnography, document analysis and poetry, each chapter seeks to "uproot the trope of home and care as stabled and fixed repository" (p. 6).

The first part of the volume, "Moving imaginaries", deals with imaginaries of home, tracing their ideals and material expressions and manifestations. This part of the volume includes insights into the social, political, and cultural imaginaries of home and shows for example how narrations and home sickness can be ways of home making (chapter 2 and 4).

The second part, called "Negotiating institutions", explores how home making takes place in places which exist beyond what we normally consider home. Here the authors write about the negotiation of home in places that operate along a logic of care (Mol, 2008). A most important example of such negotiation is found in Pasveer's analysis of four modes of (dis)entangling home and care in hospices (chapter 10). With a keen eye for ethnographic details Pasveer investigates "the in-between spaces of accessibility and control, of the private and the common and of the still living and already dying" (p. 207).

The last part of the book, "Shifting arrangements", explores in more detail how home is an always emergent quality of shifting arrangements of people, things, places and affects. Here, the trajectories of transformation of person and places are explored by Wackers in a beautiful autoethnographic account of home death (chapter 11). The transformation of the home is also under focus in chapter 14. Drawing on two case stories of families working to accommodate the growing dementia of one of their members, Ceci, Moser and Pols show how the home itself is transformed from a singular care place into one of many parameters to be tinkered with.

Unlike previous publications by the authors, care is left somewhat undertheorized in the volume - and perhaps rightly so - as it is not the focus of the volume. The authors build on Law's (2010: 69) definition of care as the work of "holding together that which does not necessarily hold together" and adds that home and care are always and already intertwined. One chapter poignantly address how age, gender and home are made together (chapter 8), and another make use of a circulation of care framework - how care unevenly flows in transnational family networks to trace the asymmetrical reciprocal exchanges of care (chapter 3). However, more current perspectives about the non-innocence of care and recent insights concerning care's exclusions (Martin et al., 2015; Murphy, 2015) are missing in this volume. According to Martin et al (2015) care has a dark side and violence is sometimes committed in the name of care. These perspectives could have generated interesting questions about potential problematic aspects at the intersections of home making and care. While I think it is important to describe good care as it is commonly "is silently incorporated in practices and does not speak for itself" (Mol, 2008: 2), issues of for example the gendered and often racial nature of care work tend to be rendered invisible in such an analysis.

Overall, the volume provides empirically meticulous and important insights and offers a compelling theoretical framework to the study of how home and homely institutions are made. 


\section{References}

Haraway D (1988) Situated knowledges: The science question in feminism and the privilege of partial perspective. Feminist studies 14(3): 575-599.

Law J (2010) Care and killing: tensions in veterinary practice. In: Mol A, Moser I and Pols J (eds) Care in practice: on tinkering in clinics, homes and farms. Bielefeld: Transcript, pp. 57-69.

Martin A, Myers N and Viseu A (2015) The politics of care in technoscience. Social Studies of Science 45(5): 625-641.

Mol A (2008) The logic of care: Health and the problem of patient choice. London: Routledge.

Mol A, Moser I and Pols J (eds) (2010) Care in practice: on tinkering in clinics, homes and farms. Bielefeld: Transcript.

Murphy M (2015) Unsettling care: Troubling transnational itineraries of care in feminist health practices. Social Studies of Science 45(5), 717-737.

Puig de La Bellacasa, M P (2011) Matters of care in technoscience: Assembling neglected things. Social studies of science 41 (1): 85-106. 